\title{
Bacterial degradation of coal discard and geologically weathered coal
}

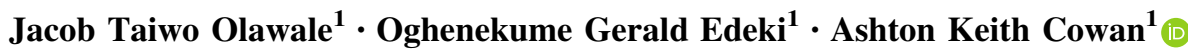

Received: 20 March 2019/Revised: 10 February 2020/Accepted: 27 February 2020/Published online: 17 March 2020

(C) The Author(s) 2020

\begin{abstract}
The biodegradation of coal discard is being intensively studied in South Africa in an effort to develop passive methods for the successful revegetation and rehabilitation of waste dumps, to mitigate pollution, and facilitate mine closure. Bacteria were isolated from slurries of coal tailings and diesel-contaminated soil, screened for coal biodegradation competence, characterized, and the colonization and degradation of coal discard and geologically weathered coal investigated using individual isolates and consortia. Ten novel coal-degrading bacterial strains were isolated and characterized, the gene sequences deposited with GenBank, and the (wild-type) strains deposited at Microbial Culture Collection, India. The results from the present work show that bituminous coal discard and geologically weathered coal is used by these isolates as carbon and energy source. Isolated strains and consortia colonized and degraded both coal substrates. Growth rate of the isolates is faster and stationery phase achieved sooner in minimal medium containing geologically weathered coal. This observation suggests that the oxygen-rich weathered coal is a more friable substrate and thus readily colonised and biodegraded. A reduction in mass of substrate is demonstrated for both individual isolates and consortia. The changes in $\mathrm{pH}$ and associated media colouration occurred concomitant with formation of humic acid-like (HS) and fulvic acid-like substances (FS) which is confirmed following analysis of these products by FT-IR spectroscopy. It is concluded that preferential metabolism of alkanes from the coal substrates provided the carbon and energy for bacterial growth and transformation of the substrates to HS and FS.
\end{abstract}

Keywords Bacteria $\cdot$ Biodegradation $\cdot$ Coal discard $\cdot$ Humic acid $\cdot$ Fulvic acid $\cdot$ FT-IR $\cdot$ Geologically weathered coal

$\begin{array}{ll}\text { Abbreviations } \\ \text { CYP } & \text { Cytochrome P450 } \\ \text { DPA } & \text { Diphenylamine } \\ \text { ECCN } & \text { EBRU culture collection number } \\ \text { FT-IR } & \text { Fourier transform infrared spectroscopy } \\ \text { FA } & \text { Fulvic acid } \\ \text { FS } & \text { Fulvic acid-like substances }\end{array}$

Electronic supplementary material The online version of this article (https://doi.org/10.1007/s40789-020-00306-3) contains supplementary material, which is available to authorized users.

Ashton Keith Cowan

a.cowan@ru.ac.za

1 Institute for Environmental Biotechnology, Rhodes University (EBRU), P.O. Box 94, Makhanda 6140, South Africa
HA Humic acid

HS Humic acid-like substances

LAC Laccase

PAH Poly aromatic hydrocarbon

\section{Introduction}

Discard coal is the low-energy-value residue after excavation of bituminous hard coal and may comprise a mix of waste coal with some soil and rock (i.e. spoil) which in South Africa, is typically stockpiled in dumps. When left for extended periods, these discard dumps tend to be a source of air pollutants and, following precipitation leach metal ions from the carbonaceous material into waterways that may 
lead to acid rock drainage and contamination of recipient water courses and streams (Claassens et al. 2006). Land devastation in regions where coal mining has taken place is well documented and serves to emphasise the need for continued effort to develop sound rehabilitation technologies to support re-vegetation and transformation of this disturbed land to a new beneficial condition (Sheoran et al. 2010; Limpitlaw and Briel 2015; Weyer et al. 2017). Biological rehabilitation has become the strategy of choice and is considered to be economic, safe, more energy efficient and environmentally compatible, and potentially capable of providing a means to convert coal discard to ash and sulphurfree products of value (Reich-Walber et al. 1997; Klein et al. 2001; Hofrichter and Fakoussa 2001; Machnikowska et al. 2002; Sekhohola et al. 2013; Cowan et al. 2016).

It has long been recognised that coal is susceptible to microbial transformation and several articles on this subject were published during the period 1908-1927 (reviewed by Klein et al. 2001). However, there was little further interest until bacteria were shown to solubilise part of the organic phase of hard coal (Fakoussa 1981). At about the same time it was reported that wood-rot fungi quantitatively solubilised the low-rank coal, Leonardite (Cohen and Gabriele 1982). This was followed by confirmation of the microbial degradation of coal by a wide variety of biocatalysts including: Streptomyces viridosporous (Strandberg and Lewis 1987), Streptomyces flavovirens (Moolick et al. 1989), Penicillium sp. (Moolick et al. 1989), Bacillus cereus (Maka et al. 1989), Arthrobacter sp. (Torzilli and Isbister 1994), Nematoloma frowardii (Hofrichter and Fritsche 1997), Aspergillus sp. (Laborda et al. 1999), Penicillium sp. (Laborda et al. 1999), Trichoderma sp. (Laborda et al. 1999), Phanerochaete chrysporium (Ralph and Catcheside 1994), Trametes versicola (Gotz and Fakoussa 1999), Pseudomonas putida (Machnikowska et al. 2002), Coriolus versicolor (Basaran et al. 2003), Trichoderma sp. (Kai-yi et al. 2009), Pseudomonas stutzeri (Singh and Tripathi 2011) and Neosartorya fischeri (Igbinigie et al. 2008; Sekhohola et al. 2014; Sekhohola and Cowan 2017). While the detail of mechanisms involved in biodegradation of coal are still to be elucidated, oxidation of sub-bituminous coal by Pseudomonas fluorescens (Hazrin-Chong et al. 2014), solubilisation of brown coal by Gordonia alkanivorans and Bacillus mycoides (Romanowska et al. 2015), the production of humic substances from low-rank coal by strains of Bacillus mycoides, $\mathrm{Mi}$ crobacterium sp., Acinetobacter baumannii, and Enterobacter aerogenes (Valero et al. 2014) together with release from liquefied coal of humic and fulvic acids by a novel recombinant Fusarium oxysporum laccase (Kwiatos et al. 2018) and other coal biosolubilization mediators (David et al. 2017), illustrate the potential to use microbes in developing sustainable rehabilitation strategies.
Biological degradation of complex hydrocarbons such as coal, crude oil, and petroleum usually requires cooperation between species or assemblages of mixed populations (Ghazali et al. 2004; Jacques et al. 2008). Thus, consortia of microorganisms appear to be more efficient as biocatalysts than individual strains (Hofrichter et al. 1999; Grinhut et al. 2007). The latter has been particularly evident in studies on the bacterial conversion of coal to methane (Lavania et al. 2014; Zhang et al. 2015; He et al. 2016). In the present work, bacteria were sourced by bio-prospecting and isolated from slurries of coal tailings, from the root zone of grasses on coal discard dumps, and from dieselcontaminated soil and screened for coal biodegradation potential in liquid medium. In this study, the molecular identification of ten coal degrading bacteria is reported. Additionally, experiments are described that were carried out to demonstrate the ability of the most active of these strains, both individually and in consort, to colonise and degrade coal. Results provide further evidence in support of formation of humic acid (HS)- and fulvic acid (FS)-like substances as products of the microbial degradation of bituminous coal discard and geologically weathered coal.

\section{Materials and methods}

\subsection{Preparation and characterization of substrates}

Coal discard was obtained from waste dumps in the eMalahleni coal fields, Mpumalanga Province, South Africa. Geologically weathered coal was sourced from the No.2 Seam, Kromdraai Section, Landau Colliery (Cowan et al. 2016). Substrates were air-dried and ground using a HP-M 100 Pulverizer (HERZOG Maschinenfabrik GmbH Co., Osnabrück, Germany) to yield particles of approximately $0.2-0.5 \mathrm{~mm}$ in diameter and sterilized by freeze thawing using liquid nitrogen (three cycles) to eliminate any in situ bacterial activity. Confirmation of sterilization was achieved by monitoring microbial growth after plating on nutrient agar (containing; $1 \mathrm{~g}$ meat extract, $5 \mathrm{~g}$ peptone, $2 \mathrm{~g}$ yeast extract, $8 \mathrm{~g} \mathrm{NaCl}$, and $15 \mathrm{~g}$ agar, obtained from Merck KGaA, Darmstadt, Germany) incubated at $37{ }^{\circ} \mathrm{C}$ for $48 \mathrm{~h}$.

Proximate and ultimate analysis of the bituminous coal discard and geologically weathered coal substrates is presented in Table 1. Analyses included determination of the amount of fixed carbon, moisture, volatile matter, and ash content and these are expressed as mass percentage. Moisture content was determined after exposure of substrate samples $(1 \mathrm{~g})$ to $105{ }^{\circ} \mathrm{C}$ for $1 \mathrm{~h}$ and the relative loss of mass reported as percentage moisture. Ash content was determined after combustion of substrate in a muffle furnace (Model JK-222 M, Jingke Scientific Instrument Co., 
Table 1 Proximate and ultimate analysis of the coal discard and geologically weathered coal substrates

\begin{tabular}{lll}
\hline Parameter & Coal discard & Geologically weathered coal \\
\hline Moisture & $8 \pm 0.70$ & $4 \pm 0.01$ \\
Ash & $35 \pm 0.70$ & $40 \pm 0.69$ \\
Volatile Matter & $39 \pm 1.70$ & $49 \pm 2.29$ \\
Fixed Carbon & $18 \pm 1.90$ & $7 \pm 2.25$ \\
Elemental C & $43.5 \pm 1.07$ & $25.3 \pm 1.74$ \\
$\mathrm{H}$ & $2.7 \pm 0.55$ & $1.4 \pm 0.39$ \\
$\mathrm{~N}$ & $1.0 \pm 0.19$ & $0.7 \pm 0.34$ \\
$\mathrm{~S}$ & $0.2 \pm 0.28$ & $0.2 \pm 0.18$ \\
$\mathrm{O}$ & $52.7 \pm 1.08$ & $72.1 \pm 1.81$ \\
$\mathrm{pH}(1 \mathrm{M} \mathrm{KCl})$ & $3.43(3.13)$ & $3.40(3.13)$ \\
\hline
\end{tabular}

Data are the mean $\pm \mathrm{SE}$ of six determinations. The mass fraction for each parameter of each substrate was determined, multiplied by 100 , and is shown as mass percentage

Ltd., Shanghai) at $815^{\circ} \mathrm{C}$. This was achieved by increasing the temperature to $400{ }^{\circ} \mathrm{C}$ for over $30 \mathrm{~min}$, then to $815^{\circ} \mathrm{C}$ for a further $30 \mathrm{~min}$, followed isothermally for $2 \mathrm{~h}$ and the residue, reported as percentage ash. Volatile matter was quantified after heating to $910{ }^{\circ} \mathrm{C}$ for $7 \mathrm{~min}$ and loss of mass reported as percentage volatile matter. The mass percentage of fixed carbon of the two substrates was determined from the expression: $[100-(\%$ moisture $+\%$ volatile matter $+\%$ ash)]. Elemental analysis of both substrates was carried out using an elemental analyser (PE 2400 CHNS/O, PerkinElmer, Waltham, MA).

\subsection{Bacterial strains and culture conditions}

Bacterial strains were sourced through bio-prospecting and isolated from slurries prepared from coal tailings and material taken from the root zones (at a depth of $\sim 15 \mathrm{~cm}$ ) of grasses growing on coal discard dumps at coal mines in eMalahleni, Mpumalanga Province, South Africa and from diesel-contaminated soil (at a depth of $\sim 15 \mathrm{~cm}$ ) collected from mechanical workshops in the Makana Local Municipality, Eastern Cape Province, South Africa. After 48 h, slurries of nutrient broth (containing $10 \mathrm{~g} / \mathrm{L} \mathrm{NaCl}, 10 \mathrm{~g} / \mathrm{L}$ tryptone powder, and $5 \mathrm{~g} / \mathrm{L}$ yeast extract, prepared by suspending solids in distilled water prior to autoclaving at $120{ }^{\circ} \mathrm{C}$ for $20 \mathrm{~min}$ ) containing $5 \mathrm{~g}$ of excavated material, were serially diluted and aliquots plated on nutrient agar and incubated for $24 \mathrm{~h}$ at $37^{\circ} \mathrm{C}$. Pure colonies were picked and after re-streaking and plating ( 3 passages), screened for coal degradation potential by monitoring the change in $\mathrm{pH}$ of a coal-containing minimal salt medium and precipitate formation on minimal salt agar medium. From a total of 72 isolates, ten bacterial strains tested positive for coal degradation potential (Table S1) and each was enriched prior to molecular characterisation. For enrichment, each isolate was successively cultivated in the presence of pulverised coal discard $(1 \mathrm{~g})$, as the sole carbon source, in sterile minimal salt medium ( $\mathrm{pH}$ 6.8) composed of $\mathrm{K}_{2} \mathrm{HPO}_{4}$ $(1.71 \mathrm{~g} / \mathrm{L}), \quad \mathrm{KH}_{2} \mathrm{PO}_{4} \quad(1.32 \mathrm{~g} / \mathrm{L}), \quad \mathrm{NHCl}_{4} \quad(1.26 \mathrm{~g} / \mathrm{L})$, $\mathrm{MgCl}_{2} \cdot 6 \mathrm{H}_{2} \mathrm{O}(0.01 \mathrm{~g} / \mathrm{L}), \mathrm{CaCl}_{2}(0.02 \mathrm{~g} / \mathrm{L})$, and $\mathrm{FeCl}_{3}$ $(0.05 \mathrm{~g} / \mathrm{L})$, to which was added $4 \mathrm{~mL}$ of trace element solution that contained $\mathrm{MnSO}_{4} \cdot \mathrm{H}_{2} \mathrm{O}(5 \mathrm{mg} / \mathrm{L}), \mathrm{NaCl}$ $(10 \mathrm{mg} / \mathrm{L}), \mathrm{FeSO}_{4} \cdot \mathrm{H}_{2} \mathrm{O}(5 \mathrm{mg} / \mathrm{L}), \mathrm{CoCl}_{2}(1 \mathrm{mg} / \mathrm{L}), \mathrm{CaCl}_{2}$ $(1 \mathrm{mg} / \mathrm{L}), \mathrm{ZnSO}_{4} \cdot 7 \mathrm{H}_{2} \mathrm{O}(1 \mathrm{mg} / \mathrm{L}), \mathrm{CuSO}_{4} \cdot 5 \mathrm{H}_{2} \mathrm{O}(0.1 \mathrm{mg} / \mathrm{L})$, $\mathrm{AlK}\left(\mathrm{SO}_{4}\right) \cdot 12 \mathrm{H}_{2} \mathrm{O} \quad(0.8 \mathrm{mg} / \mathrm{L}), \mathrm{H}_{3} \mathrm{BO}_{3} \quad(0.1 \mathrm{mg} / \mathrm{L})$, and $\mathrm{NaMoO}_{4} \cdot 2 \mathrm{H}_{2} \mathrm{O}(0.9 \mathrm{mg} / \mathrm{L})$. Where necessary, stock cultures of each isolate were maintained in $30 \%$ glycerol and stored at $-20{ }^{\circ} \mathrm{C}$.

\subsection{Molecular identification of isolated bacterial strains}

Total genomic DNA was extracted from bacteria grown on nutrient agar plates in pure culture using the methods outlined by Head et al. (1998) and Bond et al. (2002). Briefly, lysozyme stock solution $(6 \mu \mathrm{L} ; 50 \mathrm{mg} / \mathrm{mL})$ was added to a bacteria suspension in $500 \mu \mathrm{L}$ of Tris-EDTA buffer and incubated for $3 \mathrm{~h}$ at $37{ }^{\circ} \mathrm{C}$ with occasional mixing. Extracts were then subjected to five heating $\left(100{ }^{\circ} \mathrm{C}\right.$ for $\left.1 \mathrm{~min}\right)$ and freeze-thaw (liquid nitrogen followed by $80^{\circ} \mathrm{C}$ water bath) cycles, cooled to room temperature, $50 \mu \mathrm{L}$ sodium dodecyl sulphate (10\%) and $2.5 \mu \mathrm{L}$ proteinase $\mathrm{K}$ stock solutions $(50 \mu \mathrm{g} / \mathrm{mL})$ added, thoroughly mixed, and incubated overnight at $37^{\circ} \mathrm{C}$. After addition of cetyltrimethylammonium bromide $(10 \% ; 100 \mu \mathrm{L})$ and $\mathrm{NaCl}(5 \mathrm{M} ; 200 \mu \mathrm{L})$, the extracts were incubated at $55^{\circ} \mathrm{C}$ for $1 \mathrm{~h}$. An equal amount of buffer-saturated phenol, $\mathrm{pH} 8$ (Sigma-Aldrich, St Louis, MO), was then added to $500 \mu \mathrm{L}$ aliquots of each extract which were mixed for $30 \mathrm{~s}$ and centrifuged $(10,000 \times g$ for $2 \mathrm{~min})$. The upper aqueous layer was partitioned against an equal volume of phenol:chloroform:isoamyl alcohol $(24: 24: 1, v / v / v)$, mixed, and the layers separated by centrifugation as above. Upper aqueous layers were then partitioned against equal volumes of chloroform:isoamyl alcohol $(24: 1, v / v)$ until clear. To the final clear upper aqueous layer 2.5 volumes of ice-cold redistilled ethanol (96\%) was added and DNA precipitated at $-20{ }^{\circ} \mathrm{C}$ for $12 \mathrm{~h}$ and recovered by centrifugation $(10,000 \times g$ for $20 \mathrm{~min})$. Pellets were air dried and re-suspended in triple distilled water.

For molecular typing of strains, PCR was carried out by amplifying $16 \mathrm{~S}$ ribosomal DNA using the universal primer 907R (5'-CCCCGTCAATTCCTTTGAGTTT-3') and the bacterial primer GMF5 (5'-CCTACGGGAGGCAGCAG$\left.3^{\prime}\right)$ manufactured by Integrated DNA Technologies, IO 
Table 2 Identification of bacteria with coal-degrading potential. Isolates were from slurries of coal tailings, from rhizosphere of grasses on coal discard dumps, and from diesel-contaminated soil

\begin{tabular}{llll}
\hline Accessions & & Taxonomic designation (identity, \%) & Source \\
\hline MCC & GenBank & & Diesel-contaminated soil \\
\hline MCC0016 & KC620476 & Exiguobacterium strain ECCN 21b (99) & Diesel-contaminated soil \\
MCC0021 & KC620474 & Serratia strain ECCN 24b (99) & Diesel-contaminated soil \\
MCC0022 & KC620478 & Proteus strain ECCN 23b (91) & Diesel-contaminated soil \\
MCC0027 & KC620475 & Proteus strain ECCN 20b (94) & Coal slurry \\
MCC0033 & KC620473 & Citrobacter strain ECCN 19b (99) & Diesel-contaminated soil \\
MCC0034 & KC758162 & Bacillus strain ECCN 18b (98) & Coal discard slurry \\
MCC0039 & KC700329 & Bacillus strain ECCN 41b (99) & Coal slurry \\
MCC0041 & KC620477 & Escherichia strain ECCN 25b (99) & Diesel-contaminated soil \\
MCC0042 & KC700330 & Microbacterium strain ECCN 22b (99) & Coal slurry \\
MCC0062 & & Bacillus strain ECCN 26b (99) & \\
\hline
\end{tabular}

(Muyzer et al. 1995). The PCR conditions were as follows: $95{ }^{\circ} \mathrm{C}$ for $2 \mathrm{~min}, 4$ cycles of $94{ }^{\circ} \mathrm{C}$ for $30 \mathrm{~s}, 68^{\circ} \mathrm{C}$ for $45 \mathrm{~s}$, $72{ }^{\circ} \mathrm{C}$ for $1 \mathrm{~min}$, and a final extension step of $5 \mathrm{~min}$ at $72{ }^{\circ} \mathrm{C}$. PCR products were purified and subsequently sequenced using an ABI 3130XL sequencer (Inqaba Biotec, Pretoria, South Africa). Chromatograms were converted to text format using Chromas, entered into the NCBI BLAST database, the resultant sequences submitted to GenBank using BankIT, the wild-type strains deposited with the Microbial Culture Collection (MCC), Maharashtra, India, and the accession numbers and nearest taxonomic designation assigned to each bacterial isolate are shown in Table 2.

\subsection{Bacterial growth and colonisation and biodegradation of coal in liquid media}

Sterile powdered bituminous coal discard and geologically weathered coal ( $1 \mathrm{~g}$ ), a highly oxidised naturally weathered lignite-like material, were added to flasks containing $150 \mathrm{~mL}$ aliquots of minimal salt medium containing $4 \mathrm{~mL}$ trace element solution at $\mathrm{pH}$ 6.8. Bacterial inoculum was prepared from Citrobacter strain ECCN 19b, Exiguobacterium strain ECCN 21b and Serratia strain ECCN 24b, by gentle centrifugation $(2000 \times g$ for $10 \mathrm{~min})$ of $\log$ phase cultures and washing three times with sterile $0.01 \mathrm{M}$ phosphate-buffered saline (PBS; $\mathrm{pH} 7$ ) to remove any residual carbon (Igbinigie et al. 2008), and $2 \mathrm{~mL}$ equivalent to $2.8 \times 10^{11}, 6.5 \times 10^{8}$, and $2.3 \times 10^{11} \mathrm{CFU} / \mathrm{mL}$ respectively of each culture used. Also, a consortium of Citrobacter strain ECCN 19b, Exiguobacterium strain ECCN 21b and Serratia strain ECCN 24b was formulated from these log phase cultures. Following centrifugation at $2000 \times g$ for $10 \mathrm{~min}$, pellets were washed in sterile PBS $(\mathrm{pH}$
7), re-centrifuged $(3 \times)$ and the mass of each determined and the consortium established by carefully and aseptically mixing the strains $(\mathrm{g} / \mathrm{g})$ to a culture concentration of $3.20 \times 10^{6}-3.86 \times 10^{6} \mathrm{CFU} / \mathrm{mL}$ Flasks without coal discard or geologically weathered coal in minimal salt medium were used as controls. Bacterial growth and substrate colonisation and biodegradation were achieved by incubation at $37{ }^{\circ} \mathrm{C}$ for periods up to $21 \mathrm{~d}$.

Where specified, a consortium of strains of Pseudomonas aeruginosa, Pseudomonas putida and Bacillus subtilis, known to catalyze poly aromatic hydrocarbon (PAH) degradation (Yu et al. 2001; Mukherjee and Bordoloi 2012), was prepared from seed cultures as described above and used as a positive control $(+0)$.

Bacterial growth was determined by direct quantification of DNA in bacterial samples without prior isolation or purification using diphenylamine (Zhao et al. 2013). Briefly, and at specified intervals, aliquots $(1.5 \mathrm{~mL})$ of bacterial culture were harvested, centrifuged $(2000 \times g$ for $10 \mathrm{~min})$, the supernatant discarded, cell pellets washed in PBS ( $\mathrm{pH} \mathrm{7)}$ and resuspended in $3 \mathrm{~mL}$ diphenylamine (DPA) reagent (prepared by dissolving $1.5 \mathrm{~g}$ of reagent grade DPA in $100 \mathrm{~mL}$ of glacial acetic acid and adding $1.5 \mathrm{~mL}$ conc. $\mathrm{H}_{2} \mathrm{SO}_{4}$ ). At time of growth measurement, a fresh solution of $1 \mathrm{~mL}$ acetaldehyde in $50 \mathrm{~mL}$ distilled water was prepared and $0.5 \mathrm{~mL}$ added to $100 \mathrm{~mL}$ of the DPA solution. Following incubation for $1 \mathrm{~h}$ at $60^{\circ} \mathrm{C}$ the clarified supernatant was transferred to a cuvette and absorbance at $600 \mathrm{~nm}$ determined using a UV-1201 spectrophotometer (Shimadzu, Kyoto, Japan).

Change in media $\mathrm{pH}$ was monitored at regular intervals using a $\mathrm{pH}$ meter (HI $8314 \mathrm{pH} / \mathrm{mV} /{ }^{\circ} \mathrm{C}$ Meter, Hanna Instruments (Pty) Ltd) after calibration using standard buffer solutions. 
Bacterial colonisation of substrate particles was established using scanning electron microscopy. In brief, colonised particles were collected by gentle centrifugation and fixed in $2.5 \%$ buffered glutaraldehyde at $4{ }^{\circ} \mathrm{C}$ overnight. The buffered glutaraldehyde was decanted and the samples washed twice with phosphate buffer $(0.1 \mathrm{M}, \mathrm{pH} 7.3)$ and then dehydrated using a graded alcohol series. The alcohol concentrations used were $30 \%$ through absolute ethanol in increments of $10 \%$ and incubated for $10 \mathrm{~min}$ at each step. Thereafter, samples were placed into a Critical Point Dryer apparatus basket and immersed in absolute ethanol and dried at $15{ }^{\circ} \mathrm{C}$ for $2 \mathrm{~h}$. After critical point drying, the desired part of the sample was mounted onto clean specimen stubs with double-sided conductive tape and goldcoated in order to improve the secondary electron emission and to reduce charge build up. Samples were examined using a Vega 3 LMU (TESCAN, Brno, Czech Republic) analytical scanning electron microscope at $30 \mathrm{kV}$.

To determine the quantity of substrate remaining following bacterial action, residual coal was recovered by centrifugation, washed in distilled water, the pellets freeze dried, and placed in a desiccator with activated silica gel to remove excess moisture prior to gravimetric analysis (Cimadevilla et al. 2003; Elbeyli et al. 2006). FTIR spectra were recorded using a PerkinElmer Spectrum 100 instrument (PerkinElmer, Waltham, MA) with attenuated total reflectance (ATR) accessory eliminating the need for mixing of samples with KBr. The ATR accessory, fitted with a diamond top-plate, has spectral range of $25,000-100 \mathrm{~cm}^{-1}$, refractive index of 2.4 , and $2.01 \mu$ depth penetration. FTIR spectra were recorded in the range of $4000-700 \mathrm{~cm}^{-1}$.

\subsection{Analysis of humic/fulvic acid-like substances}

Humic acid-like (HS) and fulvic acid-like substances (FS) were extracted from the supernatant using essentially the method described by Janoš (2003).

Humic acid-like substances were precipitated at $\mathrm{pH} 1$, after removal of residual substrate coal discard, for $24 \mathrm{~h}$ and concentrated by centrifugation (Eppendorf Bench-top Centrifuge $5810 \mathrm{R}$, Drücken, Germany) at $4000 \times g$ for $90 \mathrm{~min}$ at $10{ }^{\circ} \mathrm{C}$. The supernatant was retained for analysis of FS and the pellet, washed three times in distilled water and then re-suspended in an equal volume of $0.5 \mathrm{M} \mathrm{NaOH}$ (1:10 ratio of material to extraction solution). After removal of particulates by centrifugation, HS and FS (in the original supernatant) were quantified by interpolation from standard curves either for Leonardite-derived humic acid or for peat-derived fulvic acid (purchased from the International Humic Substance Society, St. Paul, MN) after determining the absorbance (Thermo Aquamate, ThermoFisher Scientific, Waltham, MA) at $250 \mathrm{~nm}$.

\subsection{Statistical analysis}

All data were computed using the statistical function in Sigma Plot version 11 (Systat Software Inc., San Jose, CA). Where necessary, results were analysed by one-way analysis of variance and significant differences between measurements for each treatment determined (Holm-Sidak method; $P<0.05$ ). Data are presented as the mean of at least three determinations \pm standard error (SE).

\section{Results}

\subsection{Bacterial growth and colonization of coal substrates}

In this study use was made of the simplified DPA colorimetric method developed by Zhao et al. (2013) to estimate the growth of coal degrading bacteria. Method selection was based on wide acceptance of DNA concentration as an accurate indicator of cell number and to avoid interference from suspended coal particles. Results show that Citrobacter strain ECCN 19b, isolated from coal slurry and, Exiguobacterium strain ECCN 21b and Serratia strain ECCN 24b both isolated from diesel contaminated soil, were able to grow and proliferate when either coal discard or geologically weathered coal was used as substrate (Fig. 1a, b). However, growth of these isolates was faster and stationary phase achieved earlier in minimal salt medium containing geologically weathered coal as carbon source.

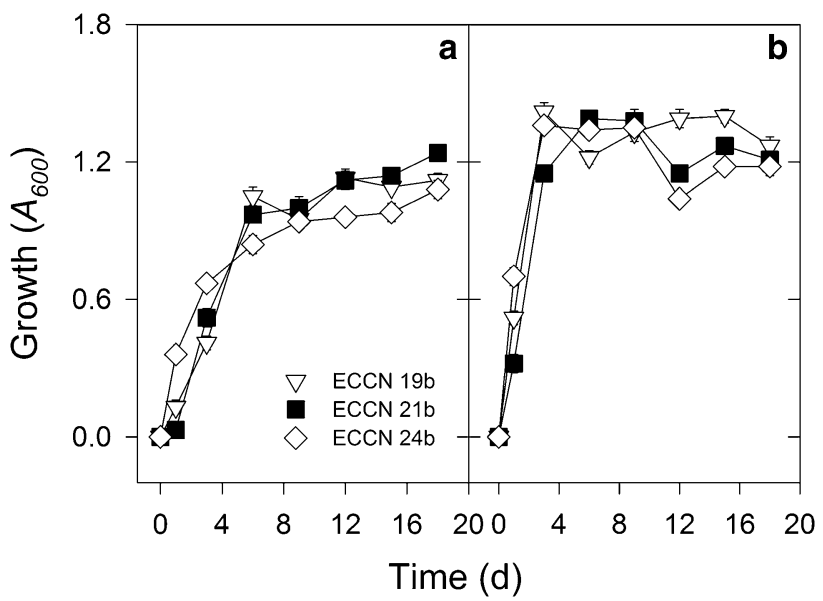

Fig. 1 Growth response of Citrobacter strain ECCN 19b, Exiguobacterium strain ECCN 21b, and Serratia strain ECCN 24b in minimal salt medium containing either coal discard (a) or geologically weathered coal (b) as the sole carbon sources. Bacterial isolates were incubated in minimal salt medium with and without coal substrate on a rotary shaker at $37^{\circ} \mathrm{C}$ and growth determined by direct quantification of DNA without prior isolation or purification using DPA. Results are expressed as the mean $\pm \operatorname{SE}(n=5)$ 


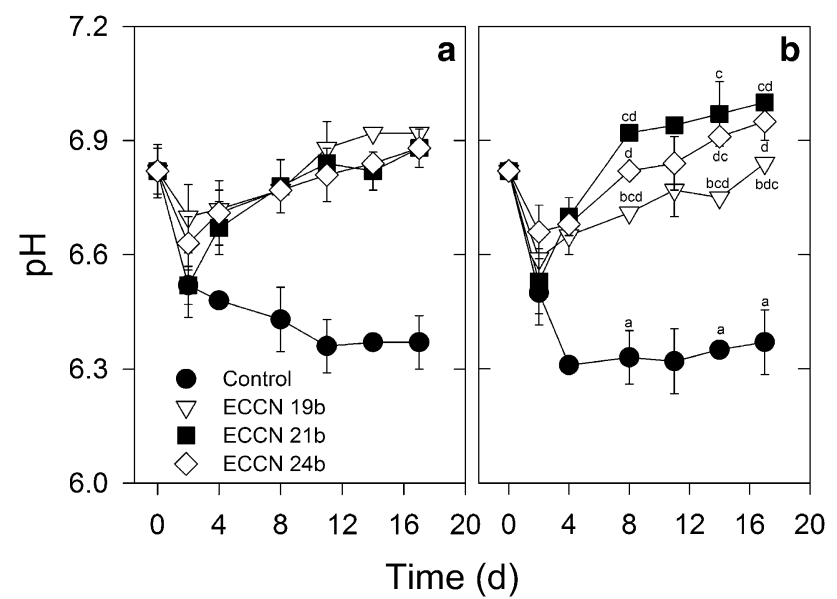

Fig. 2 Time course of the change in $\mathrm{pH}$ of minimal salt medium containing either coal discard (a) or geologically weathered coal (b) after inoculation with either Citrobacter strain ECCN 19b, Exiguobacterium strain ECCN 21b, and Serratia strain ECCN 24b. All data are the mean $\pm \operatorname{SE}(n=6)$ of three determinations and are representatives of duplicate experiments

As expected a change in $\mathrm{pH}$ of the medium was observed for all isolates irrespective of substrate (Fig. 2a, b). Following inoculation of coal-containing minimal salt medium a decline in $\mathrm{pH}$ was observed. This decline was pronounced and sustained in uninoculated control samples reflecting the acid generating potential of both coal discard and geologically weathered coal. However, in the presence of the selected coal degrading bacteria medium acidification was attenuated, transient, and returned to $\sim 6.8$ (the starting $\mathrm{pH}$ ) and then remained constant. No apparent difference in medium alkalinisation by either Citrobacter strain ECCN 19b, Exiguobacterium strain ECCN 21b or Serratia strain ECCN 24b was evident where coal discard was used as substrate (Fig. 2a). For geologically weathered coal however, alkalinisation by Exiguobacterium strain ECCN $21 \mathrm{~b}$ occurred more rapidly and was substantially greater than with Citrobacter strain ECCN 19b but similar to Serratia strain ECCN 24b (Fig. 2b).

Bacterial growth with coal as the sole carbon source (Fig. 1) and, media alkalinisation (Fig. 2) and decolourisation (Table S2) suggested that these bacterial isolates were capable of colonising both coal discard and geologically weathered coal. Scanning electron microscope examination of coal particles abstracted from minimal salt medium after inoculation revealed bacterial colonization of these substrates (Fig. 3). The isolates, Citrobacter strain ECCN 19b (Fig. 3a, b), Exiguobacterium strain ECCN 21b (Fig. 3b, c), and Serratia strain ECCN 24b (Fig. 3e, f) were equally effective at colonising coal discard and the more oxidised geologically weathered coal. Results for a consortium of the three isolates appear to show association of individual cells of Citrobacter strain ECCN 19b a Gram-

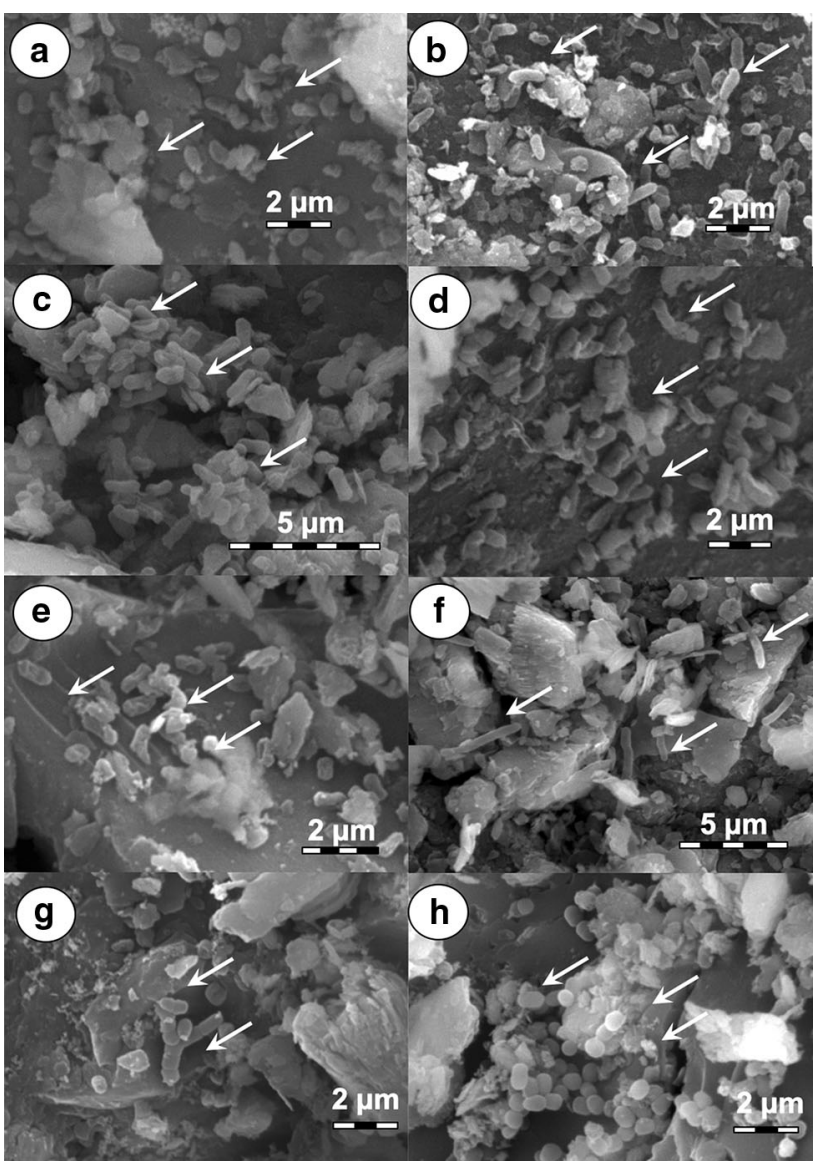

Fig. 3 Scanning electron micrographs showing colonization by cells of Citrobacter strain ECCN 19b (a, b), Exiguobacterium strain ECCN $21 b$ (c, d), Serratia strain ECCN 24b (e, f), and a consortium (ECCN 14b) of all three isolates $(\mathbf{g}, \mathbf{h})$ of either coal discard (a, $\mathbf{c}$, and e) or geologically weathered coal (b, d, and f). Substrate colonization was facilitated in minimal salt medium and particles of either coal discard or geologically weathered coal were recovered after $7 \mathrm{~d}$ at $37^{\circ} \mathrm{C}$. Arrows indicate bacterial colonization of and attachment to the coal substrate

negative flagellated bacillus, and Serratia strain ECCN 24b, a Gram-negative, rod-shaped soil bacterium with a single lateral flagellum, whereas colonies of Exiguobacterium strain ECCN $21 \mathrm{~b}$ predominate on the surface of the coal substrate (Fig. 3g, h). This is perhaps not surprising as Exiguobacterium sp. are pigmented, alkaliphilic, halotolerant, non-spore-forming Gram-positive bacilli that form flat colonies on solid surfaces (Collins et al. 1983).

\subsection{Gravimetric determination of coal biodegradation}

Biodegradation of coal discard in liquid culture by the various bacterial consortia was determined gravimetrically throughout the course of incubation and after careful recovery of residual substrate. As illustrated in Fig. 4, a substantial reduction in mass of coal discard was observed 


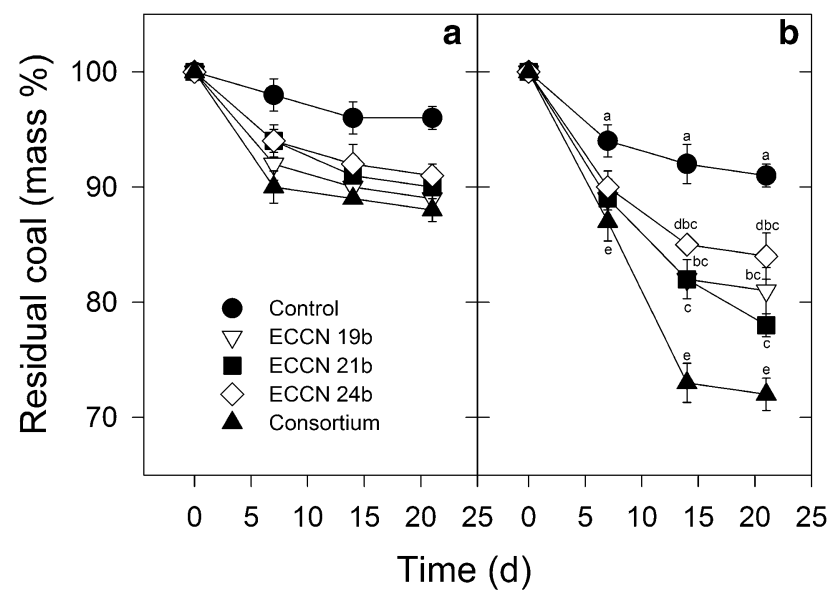

Fig. 4 Time course of the change in mass of coal discard (a) and geologically weathered coal (b) after treatment with cells of Citrobacter strain ECCN 19b, Exiguobacterium strain ECCN 21b, Serratia strain ECCN 24b, and a consortium (ECCN 14b) of all three isolates. Residual substrate was recovered, dried to a constant weight, and the mass determined gravimetrically. All data are the mean $\pm \mathrm{SE}$ of three determinations and are representatives of duplicate experiments

in the presence of either Citrobacter strain ECCN 19b, Exiguobacterium strain ECCN 21b, Serratia strain ECCN $24 \mathrm{~b}$, or a consortium of these isolates which, based on the earlier observed decolourisation (Table S2), was not unexpected. However, although average losses of up to $10 \%$ in mass of bituminous coal discard within $21 \mathrm{~d}$ were determined for each isolate and the consortium (Fig. 4a). By comparison, when the more oxidised geologically weathered coal was used, cultures of Citrobacter strain ECCN 19b, Exiguobacterium strain ECCN 21b, Serratia strain ECCN 24b, and the consortium reduced mass of this substrate by up to $30 \%$ (Fig. $4 \mathrm{~b}$ ). An attenuated reduction in mass of coal discard after inoculation either with these coal-degrading bacteria or a consortium of the isolates, suggests that substrate oxidation state plays a major role in facilitating biodegradation. No significant change in mass of either coal discard or geologically weathered coal was detected in the uninoculated controls. This latter observation, coupled with the absence of media decolouration, indicates little or no spontaneous release of organic compounds (e.g. PAH) during incubation which, might serve as an alternative substrate for bacterial growth or be utilised in the formation of co-metabolic products.

Confirmation of bacterial degradation of coal discard was obtained by detailed FT-IR analysis of the substrate prior to and following inoculation and incubation either with the consortium Citrobacter strain ECCN 19b, Exiguobacterium strain ECCN 21b, Serratia strain ECCN 24b or with ECCN13b (Table S2; a consortium of Serratia strain ECCN 24b, Citrobacter strain ECCN 19b, Escherichia strain ECCN 25b) and the positive control (a consortium comprising PAH degrading strains of Pseudomonas aeruginosa, Pseudomonas putida and Bacillus subtilis), and by comparing FT-IR spectra from inoculated and uninoculated coal discard. The results are shown in Fig. 5. FT-IR spectra of residual substrate from uninoculated media after $21 \mathrm{~d}$ incubation (Fig. 5a) and the spectrum from the raw coal discard substrate (Fig. 5b) reveal no substantial change in functional groups. In the presence of bacterial consortia however, significant shifts in functional groups were observed for coal discard exposed to either the positive control (Fig. 5c) or the consortium, ECCN 13 (Fig. 5d). Thus, while strong absorbance in the $1600 \mathrm{~cm}^{-1}$ region, consistent with alkene $(\mathrm{C}=\mathrm{C})$ stretching frequencies (Coates 1996), was observed for all treatments including the un-inoculated control, bands at $1660-1820 \mathrm{~cm}^{-1}$ denoting $\mathrm{C}=\mathrm{O}$ and COO groups (Yuan et al. 2006), were most prominent in
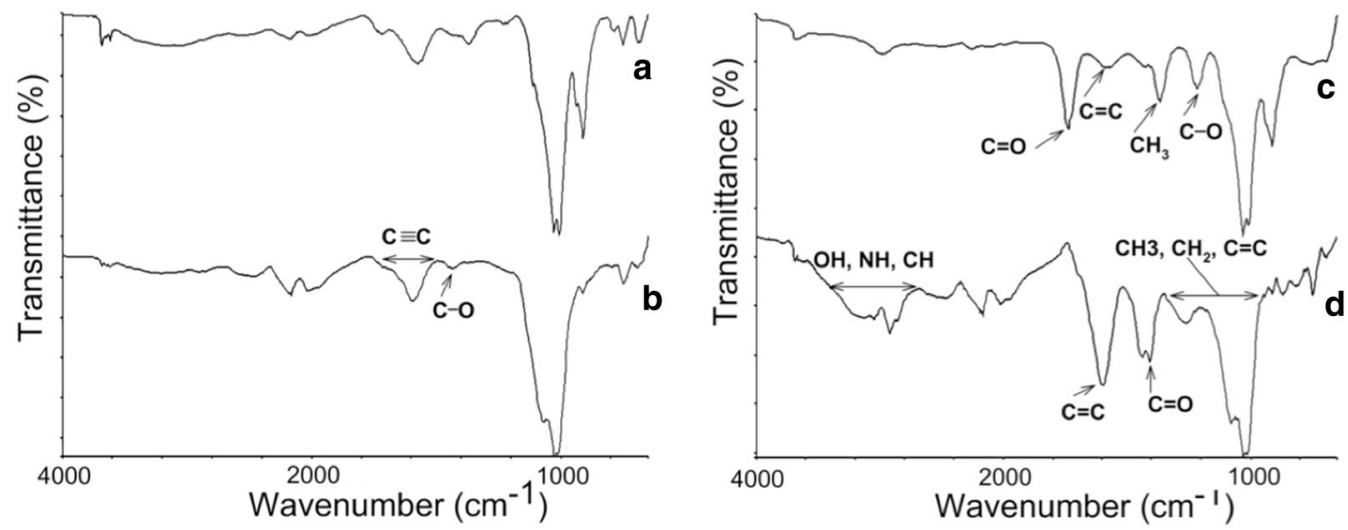

Fig. 5 FT-IR spectra of coal discard before and after treatment with bacterial isolates. Minimal salt medium containing coal substrate was inoculated and incubated at $37{ }^{\circ} \mathrm{C}$ for $21 \mathrm{~d}$. Residual substrate was recovered, dried to a constant mass, and analysed by FT-IR. Coal substrate (a); recovered residual coal from uninoculated control (b); recovered residual coal following exposure to the positive control of a consortium of P. aeruginosa, $P$. putida and B. subtilis (c); and, recovered residual after treatment with either Citrobacter strain ECCN 19b, Exiguobacterium strain ECCN 21b, and Serratia strain ECCN 24b (ECCN 14b) or ECCN 13b (d) 

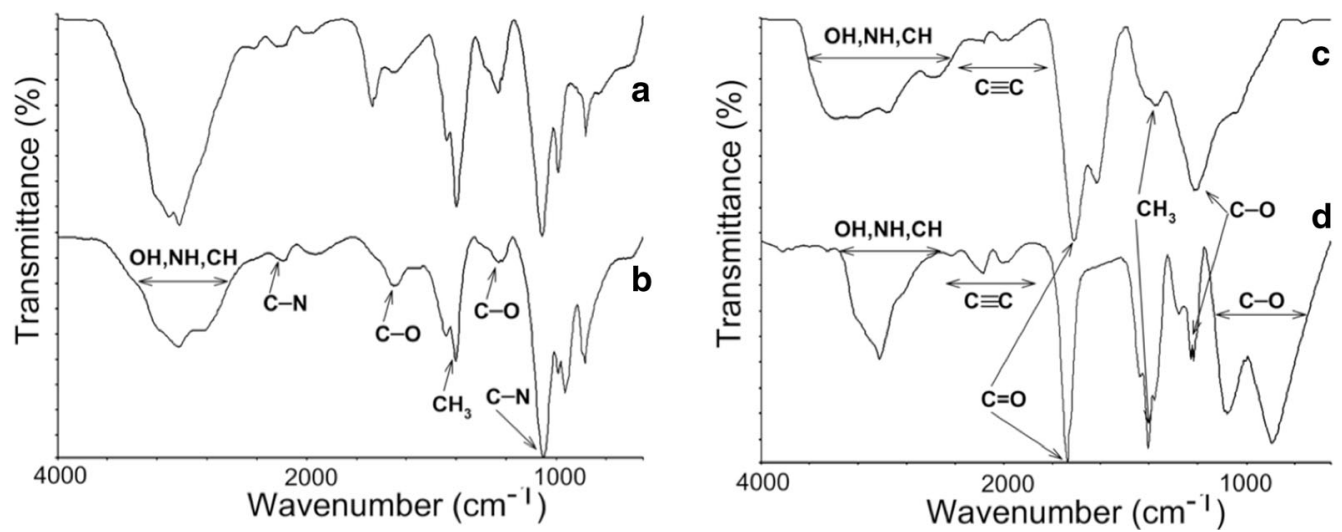

Fig. 6 FT-IR spectra of HS and FS produced by bacterial degradation of coal discard. Minimal salt medium containing coal discard was inoculated with either ECCN 13b or a consortium of Citrobacter strain ECCN 19b, Exiguobacterium strain ECCN 21b, and Serratia strain ECCN 24b (ECCN 14b) and incubated at $37{ }^{\circ} \mathrm{C}$ for $21 \mathrm{~d}$. Humic and fulvic acid-like substances were extracted, dried, and analysed by FT-IR. Commercial HA (a); HS produced from coal discard treated with bacteria (b); fulvic acids extracted from commercial humic acid (c); and, FS extracted from the HS produced from coal discard treated with bacteria (d)

substrate remaining after treatment with ECCN 13. The formation of $\mathrm{C}=\mathrm{O}$ functional groups as suggested by Coates (1996), informs that $-\mathrm{O}-\mathrm{H}$ groups will be evident in the $3400-2400 \mathrm{~cm}^{-1}$ region which were indeed observed for coal discard exposed to the consortium (Fig. 5d). Similar chemical shifts were also observed in spectra from coal discard after inoculation with a consortium of Citrobacter strain ECCN 19b, Exiguobacterium strain ECCN 21b, Serratia strain ECCN 24b (Fig. S1). Furthermore, embedded under the $-\mathrm{O}-\mathrm{H}$ stretch is the $\mathrm{C}-\mathrm{H}$ group (Coates 1996), which consists of alkane stretches $\left(3000-2850 \mathrm{~cm}^{-1}\right)$, alkene stretches $\left(3100-3000 \mathrm{~cm}^{-1}\right)$, aromatic stretches $\left(3150-3050 \mathrm{~cm}^{-1}\right)$ and alkyne stretches $\left(3300 \mathrm{~cm}^{-1}\right)$, and denotes the addition of methyl moieties to the substrate or the substitution of an atom or group by a methyl moiety. Together, these results indicate, in addition to presence of new functional groups within the coal discard, degradation of substrate.

\subsection{Formation of humic acid-like and fulvic acid- like substances}

Colouration of the minimal salt medium coupled with changes in substrate functional groups indicated bioconversion of both coal discard and geologically weathered coal into water soluble products. Spectrophotometric analysis of the aqueous fraction after inoculation and incubation with either of the substrates and the bacterial isolates revealed sustained accumulation of a product tentatively identified as a HS. Confirmation of formation of HS from coal discard in liquid medium together with formation of FS was by FT-IR spectroscopy.

Spectra of a HS extracted from the aqueous fraction after inoculation and incubation of coal substrate with bacterial consortia (i.e. ECCN 14b and ECCN 13b) revealed no substantial differences in composition based on functional group assignments when compared to that of commercial HA (Fig. 6a, b). Additionally, evidence for formation of a FS from the coal-derived soluble HS fraction was obtained. Indeed, FT-IR analysis showed that the FS extracted from commercially available HA (Fig. 6c) was similar to the FS produced during incubation of bacteria with coal discard (Fig. 6d).

\section{Discussion}

Following the successful demonstration of fungal biodegradation of hard coal in our laboratories (Igbinigie et al. 2008; Sekhohola et al. 2014), it seemed pertinent to bio-prospect for bacteria with similar coal degrading attributes. To this end, bacteria were sourced and isolated from coal slurry and diesel-contaminated soil and, following screening, several isolates were obtained with potential to catalyse the biodegradation of coal.

It has been argued that the recalcitrance of coal to biodegradation stems in part from an inability to bring metabolically active biocatalysts into direct contact with the substrate (Sekhohola et al. 2013). Results from the present study demonstrate the close association of bacterial catalysts with the two coal substrates used. Scanning electron microscope analysis confirmed surface colonisation and partial disintegration of the coal particles which has been observed in other studies (Fakoussa 1988; Laborda et al. 1997; Igbinigie et al. 2008; Hazrin-Chong et al. 2014). Earlier work showed that bacterial and fungal strains grow extensively in media containing either hard coal, sub-bituminous coal or lignite and, that extracellular polymers produced by these microorganisms appear to facilitate not only adhesion to coal particles but microbial 
attack (Laborda et al. 1997). The latter study made use of nitric acid-treated coal which has been typical of methodologies used to demonstrate biosolubilisation of this material (Catcheside and Mallett 1991; Hofrichter et al. 1997; Machnikowska et al. 2002; Shi et al. 2009; Jiang et al. 2013; Romanowska et al. 2015; Kwiatos et al. 2018). Shi et al. (2012) showed that $\mathrm{HNO}_{3}$ pre-treatment of coal decreases ash content and aromaticity but increases substrate porosity, oxygenation of aliphatic carbon, and the quantity of humic acid carbon. Also, solid state ${ }^{15} \mathrm{~N}$ NMR spectroscopy has revealed that, in addition to nitro groups from nitration of aromatic carbon, products attributable to nitrosation reactions are evident in coal pre-treated with $\mathrm{HNO}_{3}$ and, that secondary reaction products of the initially formed oximes are also produced (Thorn and Cox 2016). Although the mechanism underlying coal nitration remains poorly understood, the last step in the oxidation of phenol with nitrous acid regenerates nitrous acid which will continue to react as a nitrosating agent. In contrast, the present study used substrates not treated with $\mathrm{HNO}_{3}$. Rather, coal discard and a geologically weathered coal were used, the latter with substantially higher oxygen concentration (Table 1), decreased aromaticity and abundant C-16 and C-18 fatty acids (van Breugel et al. 2019) and, without any confounding influence of nitrous acid and its associated nitrosation reactions.

In addition to colonisation, colouration of the coalcontaining minimal medium, and changes in medium $\mathrm{pH}$ suggested that these bacterial isolates were able to degrade both of the coal substrates. While the initial decrease in medium $\mathrm{pH}$ to $\sim 6.3$ was attributed to the acid generating potential of the coal substrates (Hayatsu et al. 1978; Shi et al. 2009), subsequent bacterial-induced recovery to 6.8 and higher was taken to indicate increased medium alkalinity due to release from coal discard and geologically weathered coal of alkalinising substances such as metal oxides, carbonates, borates, borosilicate, and aluminosilicate. Furthermore, the bacterial isolates described here were shown to proliferate in minimal medium with coal as the sole carbon source. Interestingly, growth rate of these isolates was faster and stationery phase achieved sooner in minimal medium containing geologically weathered coal. This observation suggests that the oxygen-rich weathered coal is a more friable substrate and thus readily colonised and biodegraded. Confirmation of bacterial degradation of these coal substrates was by FT-IR which showed that oxidation, hydroxylation and methylation are part of the process.

Production of extracellular laccases (LAC) would appear to be a common feature of coal degrading microorganisms (Haider et al. 2013; Sekhohola et al. 2014) and recently, a Fusarium oxysporum LAC expressed in Pichia pastoris was shown to solubilise brown coal and contribute HA and fulvic acid (FA) release from the liquefied substrate (Kwiatos et al. 2018). Laccase-like activity has been detected in bacterial strains (Ihssen et al. 2015; David et al. 2017) and, a highly stable LAC was recently cloned and characterised from Bacillus subtilis (Basheer et al. 2019). While LACs oxidize non-phenolic compounds indirectly, the principal oxidative detoxification agent responsible for elimination of many hydrophobic xenobiotics is cytochrome P-450 (CYP). Several variants of this monooxygenase have been isolated and characterized (Isin and Guengerich 2007) and roles in hydrocarbon biodegradation by fungi (Harayama 1997) and bacteria (Hyman 2013) have been considered. In fact, CYP are well known to be involved in many steps in biotransformation and degradation of environmental pollutants (Kellner et al. 1997; Kelly and Kelly 2013; Khmelevtsova et al. 2017). Also, a role for selected bacterial CYPs has been emphasized: for example, in the biotechnological applications of

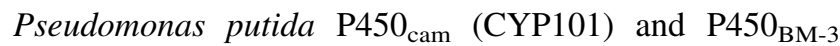
(CYP102) from Bacillus megaterium (Lewis and Wiseman 2005). In particular, attention was placed on a role for these enzymes in biodegradation due in part, to catalytic selfsufficiency and an ability to metabolize long chain fatty acids such as lauric and pentadecanoic acid. Thus, CYP102 which is covalently linked to its NADPH dependent oxido reductase redox partner has amongst the highest catalytic activity of all known P450's, with a turnover number of 4600 (Fulco 1991). It remains to be determined whether the bacteria isolated from coal slurry and diesel-contaminated soil in this study are capable of carrying out LAC- and CYP-catalysed reactions to facilitate coal biodegradation.

In addition to oxidative enzymes, hydrolytic enzymes also appear to contribute to the depolymerization of lignite and for several fungi, lignite solubilization is reported to correlate with enzymatic hydrolytic activity (Hölker et al. 1999). Later, content of HAs and water-soluble HS was shown to increase markedly while molecular mass of HA decreased in lignite depolymerized by Penicillium decumbens strain P6 (Dong et al. 2006). Depolymerization is believed to be a consequence of an esterase (Yang et al. 2018).

Taken together, the aforementioned enzymological studies indicate that the major products of microbial catalysed coal biodegradation appear to be HS and spectroscopic data obtained in the present study would seem to support this conclusion. Thus, a major product of coal discard as a result of inoculation with bacterial consortia was tentatively identified as HS. A second product, extracted from the HS-containing fraction, was identified by FT-IR as FS. Several studies have confirmed the ability of bacteria, fungi and algae to degrade HA and produce FS and, the utilisation of HA and HS by these microorganisms has also been documented (Steffen et al. 2002; Grinhut 
et al. 2007; Park and Kim 2015). Results from the present study therefore appear to support formation of HS and FS as products of the action of bacteria on coal discard and geologically weathered coal.

\section{Conclusion}

In conclusion, the present study investigated the bacterial degradation of coal in liquid medium. Consortia of bacterial isolates from coal and diesel-contaminated soil slurries were able to grow and either directly or indirectly facilitate HS- and FS formation with either coal discard or geologically weathered coal as the sole carbon source. These results contrast with previous findings which reported an inability or recalcitrance of bacteria to degrade coal (Fakoussa and Hofrichter 1999; Machnikowska et al. 2002) but support more recent observations (Hazrin-Chong et al. 2014; Romanowska et al. 2015). The most effective coal degrading consortia in the present study contained either Exiguobacterium strain ECCN $21 \mathrm{~b}$ or Serratia strain ECCN $24 \mathrm{~b}$ or both, and these reduced mass of the coal substrates by $\sim 10 \%$ and $\sim 30 \%$ respectively. Indeed, species of the alkalophilic bacterium Exiguobacterium aurantiacum are able to utilise $n$-alkanes (C9-C26) from diesel as a source of carbon and energy (Collins et al. 1983; Mohanty and Mukherji 2008). Similarly, strains of Serratia species have been identified as hydrocarbon degraders (Benedek et al. 2011). Aerobic degradation of alkanes can be catalysed by alkane monooxygenase and certain CYPs (van Beilen et al. 2006), and similar systems may supply both the carbon and energy for bacterial transformation of coal to HS and FS.

Acknowledgements Anglo American Thermal Coal, South Africa and the National Research Foundation, South Africa (IFR1202220169, Grant No. 80879) are acknowledged for financial support. Oghenekume G. Edeki and Jacob T. Olawale acknowledge financial support in the form of doctoral bursaries from Anglo American Thermal Coal and the Technology for Human Resources for Industry Programme (THRIP; TP13070820781, UID 90252).

\section{Compliance with ethical standards}

Conflict of interest The authors have declared no conflict of interest.

Open Access This article is licensed under a Creative Commons Attribution 4.0 International License, which permits use, sharing, adaptation, distribution and reproduction in any medium or format, as long as you give appropriate credit to the original author(s) and the source, provide a link to the Creative Commons licence, and indicate if changes were made. The images or other third party material in this article are included in the article's Creative Commons licence, unless indicated otherwise in a credit line to the material. If material is not included in the article's Creative Commons licence and your intended use is not permitted by statutory regulation or exceeds the permitted use, you will need to obtain permission directly from the copyright holder. To view a copy of this licence, visit http://creativecommons. org/licenses/by/4.0/.

\section{References}

Basaran Y, Denizli A, Sakintuna B, Taralp A, Yurum Y (2003) Bioliquefaction/solubilization of low-rank Turkish lignites and characterization of the products. Energy Fuels 17(4):1068-1074

Basheer S, Rashid N, Akram MS, Akhtar M (2019) A highly stable laccase from Bacillus subtilis strain R5: gene cloning and characterization. Biosci Biotechnol Biochem 83(3):436-445. https://doi.org/10.1080/09168451.2018.1530097

Benedek T, Máthé I, Táncsics A, Márialigeti K, Albert B, Lányi S (2011) Intrinsic bioremediability of petroleum hydrocarbon contaminated sites in Romania: diversity of bacterial community, catechol dioxygenase and alkane-monooxygenase genes. UPB Sci Bull Ser B Chem Mater Sci 73:51-62

Bond PL, Smriga SP, Banfield JF (2002) Phylogeny of microorganisms populating a thick, subaerial, predominantly lithotrophic biofilm at an extreme acid mine drainage site. Appl Environ Microbiol 66:3842-3849

Catcheside DEA, Mallett KJ (1991) Solubilization of Australian lignites by fungi and other microorganisms. Energy Fuels 5(1):141-145

Cimadevilla JLG, Alvarez R, Pis JJ (2003) Photoacoustic FT-IR study of weathered stockpiled coking coals. Vibrat Spectr 31:133-141

Claassens S, Jansen Van Rensburg PJ, Van Rensburg L (2006) Soil microbial community structure of coal mine discard under rehabilitation. Water Air Soil Pollut 174:355-366

Coates JP (1996) The interpretation of infrared spectra: Published reference sources. Appl. Spectr Rev 31:179-192

Cohen MS, Gabriele PD (1982) Degradation of coal by the fungi Polyporus versicolor and Poria monticola. Appl Environ Microbiol 44:23-27

Collins MD, Lund BM, Farrow JAE, Schleifer KH (1983) Chemotaxonomic study of an alkalophilic bacterium, Exiguobacterium aurantiacum gen. nov., sp. nov. J Gen Microbiol 129:2037-2042

Cowan AK, Lodewijks HM, Sekhohola LM, Edeki OG (2016) In situ bioremediation of South African coal discard dumps. In: Fourie AB, Tibbett M (eds) Proceedings, mine closure-2016. Australian Centre for Geomechanics, Perth, pp 501-509

David Y, Baylon MG, Pamidimarri SDVN, Baritugo K-A, Chae CG, Kim YJ, Kim TW, Kim M-S, Na JG, Park SJ (2017) Screening of microorganisms able to degrade low-rank coal in aerobic conditions: potential coal biosolubilization mediators from coal to biochemicals. Biotechnol Bioprocess Eng 22(2):178-185

Dong L, Yuan Q, Yuan H (2006) Changes of chemical properties of humic acids from crude and fungal transformed lignite. Fuel 85(17-18):2402-2407

Elbeyli IY, Palantöken A, Piskin S, Kuzu H, Peksel A (2006) Liquefaction/solubilization of low-rank Turkish coals by whiterot fungus (Phanerochaete chrysosporium). Energ Sour Part A 28:1063-1073

Fakoussa RM (1981) Kohle als Substrat fur Mikroorganismen: Untersuchungen zur mikrobiellen Umsetzung nativer Steinkohlen. Dissertation, University of Bonn, Germany

Fakoussa RM (1988) Production of water-soluble coal-substances by partial microbial liquefaction of untreated hard coal. Resour Conserv Recy 1:251-260

Fakoussa RM, Hofrichter M (1999) Biotechnology and microbiology of coal degradation. Appl Microbiol Biotechnol 52:25-40

Fulco A (1991) $\mathrm{P}_{450} \mathrm{BM}_{3}$ and other inducible bacterial P450 cytochromes: biochemistry and regulation. Ann Rev Pharm Toxicol 31:177-203 
Ghazali FM, Rahman RNZA, Salleh AB, Basri M (2004) Biodegradation of hydrocarbons in soil by microbial consortium. Int Biodeterior Biodegrad 54:61-67

Gotz GKE, Fakoussa RM (1999) Fungal biosolubilization of Rhenish brown coal monitored by Curie point pyrolysis/gas chromatography/mass spectrometry using tetraethylammonium hydroxide. Appl Microbiol Biotechnol 52:41-48

Grinhut T, Hadar Y, Chen Y (2007) Degradation and transformation of humic substances by saprotrophic fungi: processes and mechanisms. Fungal Biol Rev 21:179-189

Haider R, Ghauri MA, SanFilipo JR, Jones EJ, Orem WH, Tatu CA, Akhtar K, Akhtar N (2013) Fungal degradation of coal as a pretreatment for methane production. Fuel 104:717-725

Harayama S (1997) Polycyclic aromatic hydrocarbon bioremediation design. Curr Opin Biotechnol 8:268-273

Hayatsu R, Winans RE, Scott RG, Moore LP, Studier MH (1978) Characterization of organic acids trapped in coals. Nature 275:116-118

Hazrin-Chong NH, Marjo CE, Das T, Rich AM, Manefield M (2014) Surface analysis reveals biogenic oxidation of sub-bituminous coal by Pseudomonas fluorescens. Appl Microbiol Biotechnol 98:6443-6452

He H, Han Y, Jin D, Leng Y, Sun Q, Shen L, Tao X (2016) Microbial consortium in a non-production biogas coal mine of eastern China and its methane generation from lignite. Energ Sour Part A 38(10):1377-1384

Head IM, Saunders JR, Pickup RW (1998) Microbial evolution, diversity, and ecology: a decade of ribosomal RNA analysis of uncultured microorganisms. Microb Ecol 35:1-21

Hofrichter M, Fakoussa R (2001) Microbial degradation and modification of coal. In: Steinbuchel A, Hofrichter M (eds) Lignin, humic substances and coal, vol 1. Wiley, Weinheim, pp 393-427

Hofrichter M, Fritsche W (1997) Depolymerization of low-rank coal by extracellular fungal enzyme systems. II. The ligninolytic enzymes of the coal-humic acid depolymerizing fungus Nematoloma frowardii b19. Appl Microbiol Biotechnol 47:419-424

Hofrichter M, Bublitz F, Fritsche W (1997) Fungal attack on coal; modification of hard coal by fungi. Fuel Process Technol 52:43-53

Hofrichter M, Ziegenhagen D, Sorge S, Ullrich R, Bublitz F, Fritsche W (1999) Degradation of lignite (low-rank coal) by ligninolytic basidiomycetes and their manganese peroxidase system. Appl Microbiol Biotechnol 52:78-84. https://doi.org/10.1007/ s002530051490

Hölker U, Ludwig S, Scheel T, Höfer M (1999) Mechanisms of coal solubilization by the deuteromycetes Trichoderma atroviride and Fusarium oxysporum. Appl Microbiol Biotechnol 52:57-59

Hyman M (2013) Biodegradation of gasoline ether oxygenates. Curr Opin Biotechnol 24:443-450

Igbinigie EE, Aktins S, van Breugel Y, van Dyke S, Davies-Coleman MT, Rose PD (2008) Fungal biodegradation of hard coal by a newly reported isolate, Neosartorya fischeri. Biotechnol J 3:1407-1416

Ihssen J, Reiss R, Luchsinger R, Thöny-Meyer L, Richter M (2015) Biochemical properties and yields of diverse bacterial laccaselike multicopper oxidases expressed in Escherichia coli. Sci Rep 5:10465. https://doi.org/10.1038/srep10465

Isin EM, Guengerich FP (2007) Complex reactions catalyzed by cytochrome P450 enzymes. Biochim Biophys Acta 1770:314-329

Jacques RJ, Okeke BC, Bento FM, Teixeira AS, Peralba MC, Camargo FA (2008) Microbial consortium bioaugmentation of a polycyclic aromatic hydrocarbons contaminated soil. Biores Technol 99(7):637-2643

Janoš P (2003) Separation methods in the chemistry of humic substances. J Chromatog A 983:1-18
Jiang F, Li Z, Lv Z, Gao T, Yang J, Qin Z, Yuan H (2013) The biosolubilization of lignite by Bacillus sp. Y7 and characterization of the soluble products. Fuel 103:639-645

Kellner DG, Maves SA, Sligar SG (1997) Engineering cytochrome P450s for bioremediation. Curr Opin Biotechnol 8:277-278

Kelly SL, Kelly DE (2013) Microbial cytochromes P450: biodiversity and biotechnology Where do cytochromes P450 come from, what do they do and what can they do for us? Philos Trans R Soc B 368:20120476. https://doi.org/10.1098/rstb.2012.0476

Khmelevtsova LE, Sazykin IS, Sazykina MA, Seliverstova EY (2017) Prokaryotic cytochromes P450 (Review). Appl Biochem Microbiol 53(4):401-409

Klein J, Fakoussa R, Hölker U, Hofrichter M, Schmiers H, Sinder C, Steinbüchel A (2001) Biotechnology of coal. In: Rehm H-J, Reed G (eds) Biotechnology: special processes, vol 10, 2nd edn. Wiley, Weinheim, pp 155-189

Kwiatos N, Jędrzejczak-Krzepkowska M, Strzelecki B, Bielecki S (2018) Improvement of efficiency of brown coal biosolubilization by novel recombinant Fusarium oxysporum laccase. AMB Express 8:133. https://doi.org/10.1186/s13568-018-0669-1

Laborda F, Fernández M, Luna N, Monistrol IF (1997) Study of the mechanisms by which microorganisms solubilize and/or liquefy Spanish coals. Fuel Process Technol 52:95-107

Laborda F, Monistrol IF, Luna N, Fernandez M (1999) Processes of liquefaction/solubilization of Spanish coals by microorganisms. Appl Microbiol Biotechnol 52:49-56

Lavania M, Cheema S, Sarma PM, Ganapathi R, Lal B (2014) Methanogenic potential of a thermophilic consortium enriched from coal mine. Int Biodeterior Biodegrad 93:177-185

Lewis DFV, Wiseman A (2005) A selective review of bacterial forms of cytochrome P450 enzymes. Enzyme Microb Technol 36:377-384

Limpitlaw D, Briel A (2015) Post-mining land use opportunities in developing countries-a review. J S Afr Inst Min Metall 114:1-5

Machnikowska H, Pawelec K, Podgorska A (2002) Microbial degradation of low rank coals. Fuel Process Technol 77-78:17-23

Maka A, Srivastava VJ, Kilbane JJII, Akin C (1989) Biological solubilization of untreated North Dakota lignite by a mixed bacterial and bacterial/fungal culture. Appl Biochem Biotechnol 20:715-729

Mohanty G, Mukherji S (2008) Biodegradation rate of diesel range n-alkanes by bacterial cultures Exiguobacterium aurantiacum and Burkholderia cepacia. Int Biodeterior Biodegrad 61:240-250

Moolick RT, Linden JC, Karim MN (1989) Biosolubilization of lignite. Appl. Biochem. Biotechnology 20(21):731-742

Mukherjee AK, Bordoloi NK (2012) Biodegradation of benzene, toluene, and xylene (BTX) in liquid culture and in soil by Bacillus subtilis and Pseudomonas aeruginosa strains and a formulated bacterial consortium. Environ Sci Pollut Res Int 19:3380-3388

Muyzer G, Teske A, Wirsen CO, Jannasch HW (1995) Phylogenetic relationships of Thiomicrospira species and their identification in deep-sea hydrothermal vent samples by denaturing gradient gel electrophoresis of $16 \mathrm{~S}$ rDNA fragments. Arch Microbiol 164:165-172. https://doi.org/10.1007/BF02529967

Park HJ, Kim D (2015) Isolation and characterization of humic substances-degrading bacteria from the subarctic Alaska grasslands. J Basic Microbiol 55:54-61

Ralph JP, Catcheside DEA (1994) Decolourization and depolymerization of solubilized low-rank coal by the white-rot basidiomycete Phanerochaete chrysosporium. Appl Microbiol Biotechnol 42:536-542 
Reich-Walber M, Meyrahn H, Lenz U (1997) Rheinbraun's concept for power generation based on biotechnologically converted lignite. Fuel Process Technol 52:267-277

Romanowska I, Strzelecki B, Bielecki S (2015) Biosolubilization of Polish brown coal by Gordonia alkanivorans S7 and Bacillus mycoides NS1020. Fuel Process Technol 131:430-436

Sekhohola LM, Cowan AK (2017) Biological conversion of lowgrade coal discard to a humic substance-enriched soil-like material. Int J Coal Sci Technol 4(2):183-190

Sekhohola LM, Igbinigie EE, Cowan AK (2013) Biological degradation and solubilization of coal. Biodegradation 24(3):305-318

Sekhohola LM, Isaacs ML, Cowan AK (2014) Fungal colonization and enzyme-mediated metabolism of waste coal by Neosartorya fischeri strain ECCN 84. Biosci Biotechnol Biochem 78(10): 1797-1802

Sheoran V, Sheoran AS, Poonia P (2010) Soil reclamation of abandoned mine land by revegetation: a review. Int J Soil Sed Water 3:1-20

Shi K, Tao X, Yin S, Du Y, Lv Z (2009) Bioliquefaction of Fushun lignite: characterization of newly isolated lignite liquefying fungus and liquefaction products. Proc Earth Planet Sci 1(1):627-633

Shi K, Tao X, Hong F, He H, Ji Y, Li J (2012) Mechanism of oxidation of low rank coal by nitric acid. J Coal Sci Eng 18(4):396-399. https://doi.org/10.1007/s12404-012-0411-6

Singh DN, Tripathi AK (2011) Coal induced production of a rhamnolipid biosurfactant by Pseudomonas stutzeri, isolated from the formation water of Jharia coalbed. Biores Technol 128:215-221

Steffen KT, Hatakka A, Hofrichter M (2002) Degradation of humic acids by the litter-decomposing basidiomycete Collybia dryophila. Appl Environ Microbiol 68:3442-3448

Strandberg GW, Lewis SN (1987) Solubilization of coal by an extracellular product from Streptomyces setonii $75 \mathrm{~V} i$ 2. J Ind Microbiol 1:371-375

Thorn KA, Cox LG (2016) Nitrosation and nitration of fulvic acid, peat and coal with nitric acid. PLoS ONE 11(5):e0154981. https://doi.org/10.1371/journal.pone.0154981
Torzilli AP, Isbister JD (1994) Comparison of coal solubilization by bacteria and fungi. Biodegradation 5:55-62

Valero N, Gómez L, Pantoja M, Ramírez R (2014) Production of humic substances through coal-solubilizing bacteria. Braz J Microbiol 45:911-918

van Beilen JB, Funhoff E, van Loon A, Just A, Kaysser L, Bouza M, Holtackers R, Röthlisberger M, Li Z, Witholt B (2006) Cytochrome P450 alkane hydroxylases of the CYP153 family are common in alkane-degrading eubacteria lacking integral membrane alkane hydroxylases. Appl Environ Microbiol 72(1):59-65

van Breugel Y, Cowan AK, Tsikos H (2019) Geochemical study of weathered coal, a co-substrate for bioremediation of South African coal discard dumps. Minerals 9:772. https://doi.org/10. 3390/min9120772

Weyer VD, Truter WF, Lechner AM, Ungere CJ (2017) Surface-strip coal mine land rehabilitation planning in South Africa and Australia: maturity and opportunities for improvement. Resour Policy 54:117-129

Yang Y, Yang J, Lia B, Wang E, Yuan H (2018) An esterase from Penicillium decumbens P6 involved in lignite depolymerization. Fuel 214:416-422

Yu H, Kim BJ, Rittman BE (2001) The roles of intermediates in biodegradation of benzene, toluene, and p-xylene by Pseudomonas putida $\mathrm{F} 1$. Biodegradation 12:455-463

Yuan HL, Yang JS, Wang FQ, Chen WX (2006) Degradation and solubilization of Chinese lignite by Penicillium sp. P61. Appl Biochem Microbiol 42:52-55

Zhang J, Liang Y, Pandey R, Harpalani S (2015) Characterizing microbial communities dedicated for conversion of coal to methane in situ and ex situ. Int J Coal Geol 146:145-154

Zhao Y, Xiang S, Dai X, Yang K (2013) A simplified diphenylamine colorimetric method for growth quantification. J Microbiol Biotechnol 97:5069-5077 